\title{
Motivaciones políticas y sociales del renovado interés por la filosofía de la liberación y otras concepciones afines
}

\author{
Enrique del Percio \\ Universidad de Buenos Aires
}

\begin{abstract}
Resumen: Se analizan algunos factores política y socialmente relevantes que dan cuenta de la recuperación de concepciones relacionales del individuo y la sociedad, tales como las expresadas en la filosofía de la liberación, la filosofía andina, el pensamiento decolonial y otras constelaciones teóricas de matriz latinoamericana. Frente al intento del neoliberalismo de construcción de un sujeto empresario de sí mismo que se vincula con los demás en términos de competencia, surge como respuesta en Latinoamérica en general y en Argentina en particular un renovado interés por estudiar y aplicar desarrollos teóricos que privilegian una concepción del sujeto y la subjetividad como una construcción derivada de la primacía de la relación por sobre la sustancia como categoría fundacional de la realidad. Si bien esto concuerda con tendencias similares presentes en otras latitudes, en Latinoamérica se da con características propias, entre otras razones por haber sido en los países del sur de la región en donde primero se pusieron en práctica las propuestas de la escuela de Chicago.
\end{abstract}

Palabras clave: neoliberalismo, pensamiento decolonial, filosofía de la liberación, Argentina.

Abstract: This paper analyses some relevant political and social factors that give an account of the interest in relational conceptions of the individual and society, such as those expressed in the philosophy of liberation, Andean philosophy, decolonial thought and other theoretical perspectives that show a Latin American matrix. In contrast to the conception of the subject as an entrepreneur of himself who interacts with others in terms of competition, a renewed interest in studying and using theoretical approaches that privilege a conception of the subject and subjectivity as a construction derived from the primacy of the relation over the substance, understood as a founding category of reality, is becoming relevant in Latin American in general and, particularly, in Argentina. Although this process is consistent with similar tendencies in other parts of the world, it has distinctive characteristics in Latin America because, among other reasons, the agenda of the Chicago School was first introduced and implemented in the southern countries of the region.

Keywords: neoliberalism — decolonial thought — philosophy of liberation - Argentina. 


\section{PRESENTACIÓN}

Si bien se puede fijar la fecha de nacimiento del neoliberalismo en 1947 con la creación de la Sociedad Mont Pelerin, es recién a fines de los 70 del siglo pasado cuando esas ideas comienzan a tener una fuerte relevancia teórica y política. El sur de América fue la primera región en que estas dieron forma a la acción de gobierno, impuestas por las dictaduras de Chile y Argentina. La consecuencia más relevante del accionar de esas dictaduras no ha sido tanto la resultante económica, sino su incidencia en la conformación de una nueva subjetividad que perduraría hasta nuestros días. Este tema ha sido estudiado desde múltiples perspectivas ${ }^{1}$. En este trabajo procuraremos analizar otro aspecto: algunas respuestas particulares que están surgiendo contemporáneamente en el ámbito de la reflexión filosófica argentina frente a la hegemonía de las concepciones sociales y antropológicas neoliberales, congruentes con el tipo de subjetividades y de estructuras socioculturales vigentes.

\section{CONTEXTO HISTÓRICO}

Uno de los primeros en destacar que el neoliberalismo no es la mera continuidad del liberalismo clásico fue Foucault, quien señaló en su clase del 14 de marzo de 1979 en el Collège de France que la diferencia clave, la línea divisoria, pasa por la sustitución del homo economicus socio del intercambio de la antropología liberal clásica por el homo economicus empresario de sí mismo del neoliberalismo (Foucault, 2009: 265). Quizá quien mejor haya sintetizado de qué trata esto haya sido Margaret Thatcher, cuando en la entrevista realizada por Ronald Butt para el Sunday Times del 3 de mayo de 1981 afirmara que la economía es el método, pero el objetivo es el alma y el corazón. Estas ideas se habían comenzado a poner en práctica poco antes en el extremo sur de América merced a la acción de dos de las dictaduras más sanguinarias de las tantas que asolaron la región: desde abril de 1975 en el Chile de Pinochet (tras su encuentro con Miltron Friedman) y desde marzo de 1976 (el mismo año que Friedman recibía el Nobel de Economía) en la Argentina de Videla. En esta, el designio expreso de la Junta Militar era promover una profunda transformación cultural partiendo de la premisa de que las cau-

${ }^{1}$ Para no abrumar al lector, baste señalar un texto de un autor de cada uno de ambos países: Eduardo Sabrovsky (2013) y Jorge Alemán (2016) han trabajado el tema desde la filosofía política y el psicoanálisis respectivamente. 
sas del supuesto «subdesarrollo» argentino no serían tanto de índole económico como culturales.

Hay cierto consenso entre los especialistas en afirmar que la preeminencia dada a los factores culturales por sobre los políticos y económicos no tiene mayor sustento empírico pues, como señalan García Delgado y Molina (2006), el problema no consiste en una suerte de pobreza estructural inevitable en razón de la cultura propia de nuestros pueblos, sino que es una cuestión de decadencia explicable en función de las orientaciones que comienzan a tomar cuerpo precisamente desde la instauración de la dictadura. Hasta entonces, los porcentajes de distribución del ingreso eran similares a los de los países del mediodía europeo y el desempleo era casi friccional. Hasta el golpe del 76, según detallan los autores citados, Argentina tenía una pobreza del $8 \%$ y la mejor estructura distributiva del ingreso de toda América Latina. Pero a partir de esa fecha encontramos el punto de inflexión donde comienza el ascenso del modelo neoliberal que terminará favoreciendo un proceso de sobreendeudamiento, concentración de la riqueza, apertura irrestricta de los mercados con tipo de cambio desfavorable a la producción nacional, flexibilización laboral e inserción en una globalización competitiva de «Capitalismo salvaje que profundizará las asimetrías y las transferencias de recursos de la periferia al centro. Considerar esto es distinto a pensar que la inequidad es un problema cultural, de corrupción y de poca calidad institucional» (García Delgado y Molina, 2006: 247). Sin embargo, y a pesar de la evidencia en contra, es un lugar común atribuir los males de la sociedad argentina exclusivamente a su cultura (Grondona, 1999), como estrategia para no poner el foco en la responsabilidad que cabe a los sectores concentrados de la economía. En concordancia con esta postura (y con lo que luego expresara la citada líder neoliberal británica) el lema del Ministerio de Economía de la dictadura fue «Hacia un cambio de mentalidad» (Poratti, 2009: 674). En palabras de Armando Poratti, «El golpe de Estado de 1976 no termina solo con un gobierno, un sistema político o un proyecto determinado, sino con el mundo en que veníamos viviendo los argentinos, al menos desde el proyecto independentista de 1810. Esto hacía que las diferencias generacionales no significaran cortes abruptos, y que, en muchos aspectos, pudiéramos identificarnos diacrónicamente con una línea histórica, por encima de los rasgos generacionales peculiares» (Poratti, 2009: 675).

Por cierto, el paso de un capitalismo de acumulación a uno de consumo o, en otros términos, de una economía basada en la producción industrial a otra centrada en los servicios, con preponderancia de las finanzas, tiene su origen en los países centrales. El impacto de las nuevas tecnologías y la crisis del petróleo, entre otros factores, generan las condiciones objetivas para la construcción de un nuevo tipo de subjetividad. Tempranamente advertido por Habermas (1973: 195) el capitalismo tardío conlleva la crisis del 
sujeto moderno y de los vínculos que se habían forjado en los tres siglos anteriores, motivando la fragmentación individual y social característica de nuestro tiempo y conformando lo que Sloterdijk (2002) condensa en la expresión «individualismo de masas». Sin duda, esto es un factor ineludible para explicar la emergencia de la subjetividad neoliberal en los países centrales. Pero en el sur de América se estaba dando un proceso diferente: a inicios de los 70, la Unión Popular en Chile y el retorno de Perón en Argentina son indicadores del vigor que tenía una concepción del individuo y la sociedad de tipo relacional y solidario. Mientras medio siglo antes los fascismos europeos habían tratado de construir un pueblo organizando las masas desde el poder estatal (desde arriba hacia abajo), en esta región los pueblos intentaban darse una nueva institucionalidad política y económica desde abajo hacia arriba, lo que fue abortado por las dictaduras.

\section{LA FRAGMENTACIÓN DEL INDIVIDUO Y LA SOCIEDAD}

Asumir esta situación histórica no implica caer en ingenuidades de ningún tipo: no se trata de contraponer al pueblo poseedor de todas las virtudes con las dictaduras malvadas y completamente ajenas a ese pueblo. Sin entrar a definir qué entendemos por pueblo ni detenernos en esa época (pues solo interesa su mención a fin de que resulte más comprensible la génesis del rescate de las corrientes de pensamiento relacionales de matriz latinoamericana), baste con señalar que las dictaduras disciplinaron a la población atacando las estructuras sindicales, las redes solidarias, las cooperativas, etcétera. Esto generó las condiciones políticas y sociales para que los cambios que se fueron dando en el entonces llamado primer mundo impactaran también en las sociedades sudamericanas.

Si la mirada de los otros es clave en la conformación de la personalidad, hoy cada cual está sujeto a tantas miradas diferentes en los ámbitos residencial, laboral y familiar que su individualidad fragmentaria se encuentra perdida en medio de una sociedad de masas también fragmentada. Estas mutaciones se advierten principalmente en las grandes ciudades, que son las que imponen las pautas culturales e inciden en esos tres ámbitos, condicionando también la vida en ciudades chicas y en el medio rural:

1) Ámbito laboral: Si antes de los años 70 una persona de mediana edad en busca de empleo mostraba en su hoja de vida que había trabajado en tres empresas distintas no iba a ser bien visto. Por el contrario, hoy no sería favorecido por haberse desempeñado siempre en la misma empresa. Ya nadie trabaja toda su vida en el mismo lugar, y si al- 
guien lo hace, sus compañeros cambian, por lo que no se pueden establecer vínculos duraderos en el ámbito laboral.

2) Ámbito de residencia: Esto conlleva la necesidad de trasladarse de un lugar a otro en busca tanto de cercanía con el lugar de trabajo como de vivir en un espacio acorde al nuevo estatus adquirido, lo que hace imposible conocer a los vecinos y, por ende, ocurre lo mismo que en el caso anterior: no se pueden establecer vínculos duraderos de vecindad.

3) Ámbito doméstico: La alta productividad obtenida gracias al empleo de las nuevas tecnologías y de la mayor capacitación de los trabajadores requiere de un mayor consumo de productos con alto valor agregado. Una familia con diez hijos difícilmente puede cambiar de auto todos los años o salir a cenar afuera dos veces a la semana. Es preciso, por tanto, que la mujer salga de casa y vaya a trabajar. De ese modo, no solo tendrá menos hijos (que ya no son necesarios ni para morir en la guerra ni para mantener bajos los salarios industriales), sino que además sumará otro ingreso a la economía familiar. Si la mujer madre de diez hijos era maltratada por su esposo, no tenía más remedio que soportar el maltrato. Del mismo modo, el marido insatisfecho tampoco tenía ocasión de encontrar otra mujer. El mercado matrimonial era mucho más restringido: usualmente la mujer, una vez que se comprometía con un hombre (y lo habitual era que lo hiciera a edad temprana), debía casarse con él y, por tanto, desaparecía de ese mercado. Por eso, el hombre casado tampoco tenía ocasión de conocer mujeres: no las había en la fábrica, ni en la oficina, ni en la calle; apenas en el prostíbulo, pero ahí era difícil que el hombre encontrara una pareja estable que reemplazara a su esposa. El matrimonio era indisoluble.

\section{Las consecuencias sociopolíticas}

1) La cultura de la imagen: Cuando la gente trabaja toda la vida en el mismo lugar y vive siempre en el mismo barrio, conoce a sus compañeros y vecinos estableciendo un vínculo profundo y duradero. Este tipo de vínculo estimula una común preocupación por las cosas que atañen al interés colectivo. En cambio, cuando uno no conoce al otro, solo habla de banalidades. Resultado: la sociedad se vuelve superficial (Bauman, 2001). No es la televisión chatarra la responsable de la banalización de la sociedad, sino que la banalización de la sociedad genera esa televisión. La política se hace trivial de modo necesario. Los candidatos hablan de cualquier cosa menos de política: lo importante es mostrarse, estar en los medios, hablando — precisamente - de banalidades (Sartori, 1998). De modo concomitante, al no conocer nada de la trayectoria ni de los orígenes 
del otro, nos quedamos con lo que muestra, con su imagen como única referencia (Lipovetsky, 1986). El otro ya no muestra lo que supuestamente es (rey, noble o campesino: fetichización de la posición social) ni lo que tiene (fetichización de la mercancía) sino que es lo que muestra, aunque el automóvil que conduce sea alquilado y no haya pagado más que la primera cuota de la indumentaria que lleva puesta. La distinción aristotélica entre valor de uso y valor de cambio, retomada por Marx con agudeza para señalar la primacía del valor de cambio en la sociedad capitalista de acumulación, se transforma en la reversibilidad de ambos valores: el calzado deportivo de moda debe su valor de uso a su valor de cambio. No se adquiere ese calzado porque sea de buena calidad, sino porque es caro. El otro es lo que muestra y muestra lo que consume. Pero también se muestra para ser consumido.

2) El narcisismo resultante: Cuando el sistema requería familias numerosas, el varón era el proveedor del sustento. Por tanto, su poder en el ámbito doméstico era indiscutido. Él decidía lo que se podía y se debía hacer y lo que no. Se crecía con esa figura paterna, y, cuando se salía de casa, se seguía necesitando que alguien dijera qué hacer, como la maestra al frente del aula. Ya adulto, se buscaba ese padre en el gobernante, sea dictatorial (Videla, Pinochet, Franco, Stalin, Mao o Mussolini, tanto da que sea de izquierda o derecha) o democrático (Nasser, De Gaulle, Perón...). En cambio, hoy la vida de los progenitores gira en torno a los hijos. En virtud de los cambios ya analizados en el ámbito doméstico, el niño suele ser hijo único, además de único nieto y único sobrino, por lo que es el centro de atención de toda la familia amplia, incluyendo a la familia de la nueva pareja de su padre y de la de su madre. Asimismo, por primera vez en lo que se conoce de la historia de la humanidad, un infante apenas ingresado a la escuela primaria puede transmitir a los adultos conocimientos socialmente relevantes: cuando el chico de ocho o nueve años les explica a sus padres cómo bajar una aplicación para ingresar a su cuenta bancaria desde su celular, estamos en presencia de un quiebre, de una novedad radical en las relaciones intrafamiliares e intergeneracionales. En función de estas nuevas realidades, cuando ese chico sale de su casa no necesita buscar a ningún padre: se busca a sí mismo, se saca una selfie y la sube a las redes sociales. Este chico descubrió que fuera de casa no hay padre ni madre, y no siempre sabe qué hacer con este descubrimiento. De algún modo, la generación de los nacidos en torno a 1970 nacieron con los cambios en los modos de producción, mientras que hoy asistimos a los cambios en las relaciones de producción: hablamos de los hijos de los nacidos en los setenta, que fue la generación de transición, cuando todos estos cambios comenzaron.

3) El desinterés por la política: Al no haber instancias de diálogo sobre temas que afecten la vida en común, no hay un ámbito donde generar debates que permitan el desarrollo de una ideología coherente. No han desaparecido las ideologías, pero sí la co- 
herencia interna que estas tenían en los siglos XIX y Xx: hoy alguien se puede estar manifestando a favor de la libertad de cultivar marihuana junto a la misma persona que mañana puede estar en la vereda de enfrente al discutir sobre el derecho a abortar libremente. Otra causa no menor del desinterés por la política está dada por la falta de incentivos para la acción colectiva. En un contexto de fragmentación como el que hemos descripto, cuando alguien tiene algún tiempo libre, en lugar de preocuparse por informarse acerca de la trayectoria o la propuesta de los distintos partidos o candidatos, prefiere destinar ese tiempo a actividades que le deparan una mayor satisfacción individual. Pero ese individuo siente una cierta culpa por no hacer nada por cambiar la realidad, e incluso por no asumir ciertas responsabilidades sociales como pagar sus impuestos o tener en blanco a sus empleados, mas como se cree una buena persona, encuentra en la corrupción de los políticos una inmejorable excusa para sentirse en paz con su conciencia. La única información que le interesa es la que le permite confirmar la belleza de su alma en contraste con la inmundicia de los políticos. Por su parte, los medios de comunicación le darán lo que él quiere recibir: solo noticias negativas. El escándalo tiene más índices de audiencia que el debate serio y el diálogo constructivo. Eso genera una espiral en virtud de la cual muchas personas realmente honestas se retraen de participar de manera activa en política, dejando el campo a otros que no tienen mayor interés por el bien común. Esto último no es del todo nuevo. Ya en los años veinte del siglo pasado lúcidos pensadores como Pareto, Michel o Mosca habían explicado los problemas de la democracia... y llegó el fascismo como respuesta. Lo que es nuevo es que al haber descubierto que no hay un padre fuera de casa ya no hay lugar para un Mussolini (Hirschman, 1991). Por supuesto que siempre puede aparecer un líder carismático con caracteres paternalistas, pues por definición el carisma irrumpe como excepción sin tener en cuenta las tendencias de la historia, pero no podrá ejercer esos caracteres de un modo tan claro como los líderes de otrora ni le va a resultar sencillo hacer rutinario ese carisma.

La presencia de un padre fuerte y su correlato social y las ideologías tradicionales establecían claramente lo bueno y lo malo, lo correcto y lo incorrecto, lo permitido y lo prohibido. Generaban estructuras dicotómicas que anulaban la percepción de la complejidad de la vida individual y de la existencia en común. Hoy vale recordar la sentencia marxiana, no por reiterada menos potente: «Todo lo sólido se desvanece en el aire». Desaparecieron los fundamentos de las ideologías tradicionales de matriz europea y, por eso, la vieja Europa y su retoño norteamericano perdieron la brújula.

Por otra parte, la desaparición de los fundamentos no implica la desaparición de los fundamentalismos, sino que, por el contrario, en un intento desesperado por imponer un sentido a una vida en común que pareciera dejar de tenerlo, muchos se lanzan a la nega- 
ción del pluralismo y de la diferencia. En palabras de Chantall Mouffe, «Esta situación es peligrosa para la democracia, pues crea un terreno favorable para los movimientos políticos de extrema derecha o los que apuntan a la articulación de fuerzas políticas en torno a identidades nacionales, religiosas o étnicas. En efecto, cuando no hay apuestas democráticas en torno a las cuales puedan cristalizar las identificaciones colectivas, su lugar es ocupado por otras formas de identificación de índole étnica, nacionalista o religiosa» (Mouffe 1999; 17).

\section{MATRIZ CULTURAL Y SUBJETIVIDAD NEOLIBERAL}

Como señalamos, estos factores resultan insoslayables para tratar de comprender las bases sociales y antropológicas sobre las cuales se erige un modelo de subjetividad y de socialidad que articula (o pretende articular) un individuo empresario de sí mismo, consumidor y hedonista, en reemplazo de la sociedad dividida en empresarios-burgueses y trabajadores-proletarios, apoyada en una ética ascética del ahorro y el trabajo como valores fundacionales, propia del liberalismo clásico. Ahora bien, en el caso argentino, la presencia de movimientos políticos, sociales, sindicales, religiosos y culturales de fuerte base solidaria y popular dificultó la conquista «del corazón y el alma» en 1976 y aún hoy sigue siendo un obstáculo que los sectores interesados en imponer un modelo neoliberal tienen que superar: se puede intentar instituir una nueva subjetividad, pero siempre hay un núcleo de resistencia que impide que el crimen sea perfecto ( $c f r$. Alemán, 2016).

Resulta imposible explicar cualquier fenómeno aislado de resistencia a los intentos hegemónicos del neoliberalismo sin comprender las concepciones de lo popular en Argentina, para lo que no es necesario entrar en el difícil terreno de las definiciones, sino que basta con quedarse en el de las descripciones ${ }^{2}$. En efecto, el sustrato histórico-cultural de lo llamado popular en Argentina se conforma principalmente con la confluencia de las culturas andinas, guaraníticas, afros y criollas. Todas ellas tienen análogas concepciones relacionales y solidarias, opuestas de forma intrínseca a un tipo de subjetividad que concibe al individuo como empresario de sí mismo. Asistimos en los últimos años a un resca-

${ }^{2}$ Por si hiciera falta, vale señalar que la noción de pueblo más usada en Argentina nada tiene que ver con las concepciones fascistas, tales como el volk hitleriano o el popolo mussoliniano. Asimismo, rescatar el concepto de popular no tiene necesariamente que ver con la defensa de populismos de ninguna índole. La polisemia de ambos conceptos y la dificultad para dar una definición precisa no merman su potencialidad descriptiva. Por el contrario, quizá sea precisamente esa polisemia y esa dificultad lo que ameritan su empleo tanto por parte de la filosofía política (Cullen, 2017: 411) como de las ciencias sociales (Del Percio, 2014: 191). 
te de esas subjetividades asumidas como matriz de nuestra cultura. En tal sentido, cabe señalar la importancia que vuelven a adquirir algunas corrientes de pensamiento basadas en esta matriz y surgidas hace algunas décadas, como la filosofía y la teología de la liberación ${ }^{3}$, así como la emergencia de nuevas constelaciones teóricas tales como el pensamiento decolonial, cuya creciente presencia se manifiesta en áreas tan diversas como la filosofía, la literatura, las ciencias sociales y políticas, la economía, la historia, etc. ${ }^{4}$.

Es llamativo el auge que tienen estas ideas, a pesar de la oposición de los ámbitos académicos establecidos y de buena parte del sistema mediático. La profusión de textos publicados, congresos y jornadas pletóricos de participantes, en los que muchas veces no se da acreditación alguna, son algunos de los elementos que podemos tomar como indicadores de este auge.

Trataremos de señalar ciertos caracteres distintivos de estas corrientes teóricas, que se entienden mejor si se los compara con los caracteres propios de las filosofías de matriz europea. Por razones de espacio se realizará un esquema sucinto que, como todo esquema, sirve para tratar de entender la realidad, pero no para dar cuenta de toda ella, asumiendo el problema de toda categorización dicotómica: tal como ocurre con los tipos puros weberianos, que sirven para tratar de comprender la realidad, pero no existen como tales. No existe algo así como, por ejemplo, una oposición real entre sustancia en Europa y relación en Latinoamérica, sin embargo, esta dicotomía sirve para comprender mejor las diferencias y, paradójicamente, también las similitudes.

\section{LAS DISTINTAS FILOSOFÍAS}

En la célebre tesis xi sobre Feuerbach, Marx dice «Los filósofos no han hecho más que interpretar el mundo, pero de lo que se trata es de transformarlo». Ahora bien: si aceptamos que la realidad social es en buena medida una construcción discursiva, debemos concluir que la acción de interpretar el mundo es a la vez un modo de construirlo y,

${ }^{3}$ Una de cuyas manifestaciones más conocidas (aunque por cierto no la única) es la teología popular de la liberación, que está en la base de la doctrina que va estableciendo el papa Francisco (Cuda, 2016).

${ }^{4}$ La producción es enorme y la cita de cualquier exponente de esta tendencia es una injusticia para quien no fuese citado. Hecha esta salvedad, me limitaré a mencionar a Walter Mignolo, quien emplea el concepto a partir de la influencia del pensamiento poscolonial, a su vez tributario de los estudios culturales, propios del ámbito anglosajón. Al entrar estas ideas en contacto con la tradición de la filosofía de la liberación van a dar lugar al llamado «giro decolonial». Una buena introducción puede verse en Castro Gómez y Grosfoguel (2007). 
por consiguiente, de transformarlo. Asimismo, al no haber un punto cero, un lugar fuera de él desde donde se lo pueda interpretar, todo intérprete es a su vez producto de un haz de interpretaciones previas. En esa construcción, la filosofía ocupa un lugar privilegiado, tanto por ser su fundamento teórico como por ser la disciplina encargada de poner en conceptos esos fundamentos teóricos no siempre explicitados en otras áreas del conocimiento. Por lo tanto, cuando se habla de la filosofía de matriz europea como la filosofía, se pretende establecer un modo peculiar de concebir y construir el mundo como si fuera el único modo válido de hacerlo, olvidando o ignorando otras filosofías. Vale aclarar que, recíprocamente, cuando hablamos por ejemplo de filosofía andina, tupí-guaraní o bantú no estamos haciendo referencia a una supuesta «esencia pura» que habría que rescatar del olvido, pues nosotros, intérpretes de esos otros pensamientos, ya estamos contaminados por la filosofía europea en cuyo seno nos formamos. No existe un pensamiento puro o incontaminado, y mucho menos en la Argentina, que recibió y sigue recibiendo desde hace al menos cinco siglos invasiones y aportes migratorios $-\mathrm{y}$, por ende, culturales - de todas las latitudes. Imposiciones, resistencias, diálogos y cruces de todo tipo generaron - y continúan generando - modos diversos de conocer y producir la realidad. Hacer filosofía desde Latinoamérica en general y desde Argentina en particular no consiste ni en copiar acríticamente lo producido en el norte ni en el intento romántico de rescatar supuestas raíces de una filosofía autóctona. Consiste en pensar a partir de esto qué somos: ni occidentales con presunto derecho a dominar la tierra en nombre de Dios, de las luces de la razón o de la democracia y del mercado, ni pueblos de la aurora depositarios de saberes arcanos destinados a salvar el planeta del capitalismo predador.

Este modo particular de ser nos pone en una buena posición para entender y hacernos cargo de que todo pensamiento es un pensamiento situado, que la gravitación del suelo no solo atañe a las cosas, sino también a los pensamientos. Para decirlo en palabras de Kusch: «Y ese suelo así enunciado, que no es ni cosa, ni se toca, pero que pesa, es la única respuesta cuando uno se hace la pregunta por la cultura. Uno piensa entonces qué sentido tiene toda esa pretendida universalidad enunciada por los que no entienden el problema. No hay otra universalidad que esta condición de estar caído en el suelo, aunque se trate del altiplano o de la selva» (Kusch, 1976: 110). No se trata de un suelo/fundamento en el que somos (lo que nos llevaría a un pensar esencialista) sino del suelo en el que estamos sien$d o^{5}$, un suelo sin el cual no habría relación posible con los demás ni con el cosmos.

${ }^{5}$ El verbo ser es una particularidad de las lenguas indoeuropeas que dificulta gravemente la comprensión dinámica e inestable de la existencia que se percibe, por ejemplo, en la noción tan empleada por Kusch y las filosofías latinoamericanas de estar siendo. Citamos a propósito a Kusch (1922-1979) pues es uno de los «filósofos malditos» cuya sola mención significó durante la dictadura —e incluso después — la exclu- 
En cuanto a los modos de hacer filosofía, la de matriz europea se hace en ámbitos académicos, donde la universidad es el lugar privilegiado. La filosofía deviene una profesión más y, como tal profesión, se equipara al dominio de una técnica. Por eso, la filosofía académica tiende a privilegiar los aspectos técnicos (cómo filosofar) por sobre los aspectos vivenciales (sobre qué filosofar) contribuyendo a generar la ilusión de una posibilidad de pensar en forma pura, con independencia de toda imbricación en un tiempo y un espacio dados. Dejemos hablar a Kusch (1976): «Esa traducción de la problemática a lo visible, para lo cual nos ayuda la técnica, traducción que nos sirve para lograr cierta capacidad de manipulación de los medios y de la realidad, hace que se pierda precisamente el filosofar. Servirá en todo caso para hacer filosofías, lo cual no es lo mismo que filosofar, ya que se concreta solo al recuerdo de un sinnúmero de técnicas acumuladas a través del tiempo en un mundo como Occidente, que fue precisamente el creador de la técnica. El filosofar así no es más que una manipulación técnica. De ahí la suposición de que pudiera haber una profesionalidad del filósofo: pero una profesionalidad enquistada, autosuficiente, que a nadie sirve en América [...] una actividad estéril en sí misma, o mejor esterilizada y aséptica por una reiteración académica» (Kusch, 1976:11).

\section{EL PROBLEMA DEL FUNDAMENTO}

Debo pedir disculpas a quien está leyendo esta revista de ciencias sociales por seguir discurriendo sobre cuestiones filosóficas, pero al habernos propuesto desentrañar algunos de los factores de la creciente presencia de estas constelaciones de pensamiento que pivotan en torno a la primacía de la relación sobre la sustancia, al estar sobre el ser, y que no priorizan la pregunta por el fundamento metafísico, no queda más remedio.

Precisamente esta última cuestión, el problema del fundamento — de las cosas, la política, el derecho y la sociedad - es una de las cuestiones donde se advierte con más fuerza que pensar es siempre un pensar situado de manera geocultural. Y que pensar el mundo es, a la vez, participar en la construcción del mundo. En efecto, cuando el sujeto moderno se pregunta por qué es el ente y no más bien la nada, llega a advertir que no hay un fundamento último de la realidad, que las cosas y nosotros mismos podríamos no

sión de los claustros académicos. Basta con remitirse a cualquier buscador de internet para ver cómo crece el interés por este y otros autores ligados a la llamada filosofía de la liberación tales como Enrique Dussel, Juan Carlos Scannone, Arturo Andrés Roig, Mario Casalla, Carlos Cullen o Armando Poratti, por citar algunos de los filósofos argentinos más representativos de las distintas vertientes de esa línea de pensamiento. 
haber sido. Entonces ese sujeto (conquistador y propietario, de matriz cultural europea) tiende a pensar que todo es absurdo, que nada tiene sentido. En cambio, las gentes de América Latina tienden a pensar que si no hay fundamento la existencia es gratuita y, por lo tanto, puede o no tener sentido, pero lo importante es que las cosas y las gentes están siendo. A su vez, la noción de gratuidad conlleva una actitud de gratitud, como acontece por ejemplo en las culturas andinas, en las que se agradece de forma ceremonial a la Pachamama y al Inti ${ }^{6}$ a través de las ofrendas rituales por todos los beneficios recibidos, con características distintas de las celebraciones latréuticas o propiciatorias de otras culturas, como la bantú o las europeas premodernas (Esterman, 1998: 234).

Como para el europeo medio la existencia es existencia sustancial, le resulta difícil pensar en la sustancia como derivada de la relación: lo que no tiene existencia sustancial no existe. Es la consecuencia que sacan algunos intelectuales puestos a filosofar a partir de los hallazgos de la física cuántica: si no hay partículas elementales (átomos o lo que sea) no hay nada. En palabras de un personaje de Houellebecq (1999): «Hay que renunciar al concepto de partícula elemental que posee propiedades intrínsecas en ausencia de cualquier observación. En este caso había que enfrentarse a un profundo vacío ontológico [...] renunciando definitivamente a la idea de realidad subyacente». ¿Por qué no pensar que si no hay sustancia es porque hay relación, o que si no hay fundamento es porque hay gratuidad? A diferencia de las corrientes dominantes en el pensamiento europeo, las filosofías de cuño andino, bantú u oriental no tienen inconveniente en aceptar esto» (cfr. Dussel, 2001).

Aclaremos esto con un ejemplo: para un tipo de pensamiento muy común en el Occidente desarrollado, el ecosistema es o bien una suma de entes con existencia sustancial que se relacionan (un árbol, más otro árbol, más el río, más el aire, más la tierra, más los animales... sustancias que preexisten al ecosistema), o bien una suerte de megasustancia (Gaia, Gea, etc.), siendo las cosas, las plantas, los peces, las aves, los minerales y nosotros mismos solo partes de esa gran sustancia. En cambio, para otras metafísicas como la andina, las cosas son porque tienen relación: la Pachamama no es una sustancia que existe por sí misma, sino que es en sí misma una relación (Estermann, 1998: 95) anterior a la sustancia. De manera análoga, en el marco de la filosofía bantú se entiende que para educar a un niño hace falta un pueblo entero, del mismo modo que para que crezca un árbol hace falta lo que nosotros llamaríamos todo un ecosistema. Es decir, el

${ }^{6}$ La Pachamama equivaldría al concepto occidental de ecosistema y el de Inti al de sol, pero entendiendo que en ambos casos estamos hablando de entidades relacionales y complementarias, no de sustancias, personas o cosas. 
niño y el pueblo existen, pero no como sustancias, sino como relación, lo mismo que el árbol con respecto al ecosistema y recíprocamente.

Hoy se cobra consciencia de la falta de un fundamento sustantivo que va más allá de la mera incertidumbre, asumiendo la radical contingencia de la vida individual y de la vida en común. Se descubre, en suma, la radical contingencia de la existencia toda: es el ente, pero bien podría ser la nada. Si bien no son pocos los pensadores que vienen advirtiendo esto desde hace no poco tiempo (ya citamos a Marx con aquello de «Todo lo sólido...»), recién ahora estas preocupaciones definen lo que podríamos llamar el talante metafísico de las sociedades hegemónicas. Todas las sociedades tienen un modo de abordar el ser y la existencia: ese particular talante no es privativo de los europeos. Sin embargo, es plausible pensar que la pregunta más radical por el ser sea de matriz europea, puesto que la pregunta más radical por la nada quizá también lo sea (Casalla, 1998). Lo que ocurre es que a otros pueblos nunca les preocupó tanto esto, precisamente por advertir que las cosas no son, sino que están siendo. «La rosa es sin por qué. La rosa florece porque florece»: si esta frase de Silesius impactó tanto a Heidegger no fue porque en otras latitudes nadie se lo había planteado, sino porque no se le asignó al ser y a la nada la misma importancia ${ }^{7}$, y la preocupación por el fundamento es propia de aquelos talantes metafísicos que creen que lo que no tiene fundamento es absurdo, no de los que piensan que lo que no tiene fundamento es porque es así.

Por cierto, no es lícito encerrar en bloque a toda la filosofía occidental en este modelo esquemático, aunque sí se puede aceptar la vigencia de lo que, siguiendo a Scannone (2005), llamamos paradigmas geoculturales y epocales, que influyen más o menos, según los distintos autores.

\section{LA DISYUNTIVA NEOLIBERAL: INDIVIDUALISMO O COLECTIVISMO}

Los clásicos del neoliberalismo como Hayek, Nozick o Popper plantean una dicotomía fundacional: o lo que existe (la sustancia) es el individuo, o lo que existe es la colectividad. $\mathrm{O}$ uno u otro: no existe una síntesis superadora de este antagonismo. Por eso, toda concesión a la colectividad, así sea en términos de «justicia social», no es más que el inicio de un camino que desemboca en la servidumbre (Hayek, 2007). En términos políticos, la opción sería liberalismo o socialismo.

7 Como señala Poratti (2009) la dicotomía principal para casi todas las culturas no es ser —nada, sino cosmos- caos. 
En cambio, el pensamiento popular americano, en lugar de compartir la obsesión del pensamiento occidental por encontrar la sustancia y la esencia en todo, forma parte de las tradiciones filosóficas para las que la relación es previa a la sustancia. Desde allí podremos encontrar conceptos adecuados para describir algunas alternativas políticas argentinas, en general definidas apresuradamente como populistas, por no entrar en los moldes prefijados del liberalismo clásico, el neoliberalismo o los socialismos de matriz europea.

\section{SOCIEDAD E INDIVIDUO COMO RELACIÓN}

En efecto, a partir de una visión relacional, es posible afirmar que el pueblo o la comunidad existen sin que su existencia niegue al individuo o viceversa. Claro que esto es muy difícil de aceptar para el pensamiento europeo dominante. Si hay relación dirán - es porque hay algo (sustancias) que se relaciona con otro algo. Esto es lo que lleva a tantos excelentes filósofos políticos contemporáneos a desvivirse por encontrar un fundamento a la sociedad y a la política y, al no encontrarlo, en lugar de aceptar que las cosas son porque sí, terminan negando la sociedad y la política. Si no hay fundamento es porque hay gratuidad. Un pensamiento abierto a otros modos de entender la realidad, como es el que surge de asumir la fraternidad como eje para pensar la política y la sociedad, pone en evidencia la esterilidad de la búsqueda obsesiva del fundamento.

La categoría «relación» como anterior a la sustancia está incorporada en la forma de entender el mundo y la sociedad por parte de nuestros pueblos. No es el de nuestra gente un pensamiento antisustancialista, sino que entiende que hay cosas y que estas tienen su sustancia, pero asumiendo que la sustancia se deriva de la relación y no a la inversa. Vale insistir en que esto es la expresión en conceptos filosóficos de conocimientos, haceres y saberes que los pueblos expresan de modo más vivencial que teórico. En palabras de Alejandro Moreno (1995: 395): «El hombre de pueblo no es un ser-en-el-mundo sino una relación viviente, que existe, en tal caso. No es subjetividad ni racionalidad ni individuo, sino relación. En la relación han de deconstruirse y construirse - no reconstruirse - la subjetividad, la racionalidad y la singularidad». No se trata de un modo de superación de la antinomia colectividad vs. individuo, sino de una explicitud de esa tensión permanente. Ni la sociedad es la suma de sujetos/sustancias ni el individuo es solo una parte de un megasujeto.

En tal sentido, una lectura crítica y no ingenua del pensamiento popular tal como, por ejemplo, la que propone Kusch (2008), nos lleva a entender que las concepciones predominantes en los estratos populares argentinos, con su carga de resistencia al tipo 
de subjetividad individualista, competitiva y emprendedora propia del neoliberalismo, conllevan un potencial de resistencia y de propuesta que bien vale la pena explorar. Claro está que se debe evitar caer en esas posturas naif que consideran todo lo popular/latinoamericano como bueno y todo lo moderno/europeo como malo. Ese tipo de planteos carece de validez empírica, sentido teórico y sustento ético, por lo que no vale la pena detenerse a analizarlos. Pero sí es pertinente recuperar aspectos del pensamiento popular que permiten pensar la situación contemporánea no solo de y para Argentina sino, sobre todo, desde Argentina.

\section{LA FRATERNIDAD}

Dicho esto, cabe entonces postular que esa concepción popular/relacional asume los ideales de las democracias modernas resumidos en la trilogía libertad-igualdad- fraternidad, pero resignificándolos al tomar como inicio de la reflexión a este último ${ }^{8}$.

Rómulo y Remo, Caín y Abel, Jacob y Esaú, Tupí y Guaraní, Manco Capac y sus hermanos: en todas las latitudes encontramos mitos de origen que nos refieren peleas entre hermanos, que a veces llegan incluso al fratricidio. La experiencia cotidiana confirma que los hermanos se pelean. Sin embargo, en contra de toda evidencia, las madres insisten en decirles a sus hijos que no deben pelearse, sino que deben quererse como hermanos. Asimismo, cuando dos amigos quieren indicar que su amistad es muy fuerte, dicen que son como hermanos 9 .

Ocurre que la hermandad o fraternidad puede entenderse en dos sentidos distintos: o bien como aquello que efectivamente es o como aquello que querríamos que fuese. En el primer caso, la lucha entre hermanos nos pone frente a un dato de la realidad: las relaciones horizontales estimulan el conflicto. En el segundo caso, estamos frente a un anhelo: si pudiésemos evitar el conflicto, todos seríamos más felices. Si extrapolamos el concepto de fraternidad del ámbito doméstico al terreno político, cuando hablamos de

${ }^{8}$ Entendida, obviamente, como fraternidad/sororidad, dada la importancia que el principio de complementariedad tiene en el pensamiento popular, estimo que no permite pensar lo masculino aislado de lo femenino ni a la inversa (Estermann, 2011: 38).

${ }^{9}$ En rigor, se trata de una catacresis, es decir, de un topo retórico, una suerte de metáfora, consistente en usar una palabra con un sentido diferente al que originariamente le corresponde, con el fin de describir algo que carece de nombre particular. Por ejemplo, cuando hablamos del cuello de una botella o del brazo de un sillón, es evidente que no estamos hablando de cuello o pata en el sentido originario, como cuello o pata de un ser viviente, pero no existe otra palabra para referirnos a eso, por lo que no tenemos más remedio que emplear ese término. Para un análisis detallado de las implicancias de la fraternidad, $c f r$. Del Percio (2014). 
fraternidad universal podemos hacer referencia o bien a: a) la condición originaria de la sociedad: no hay padre ni madre, por tanto, el conflicto está siempre ahí, en forma manifiesta o latente, o bien $\mathrm{a}$ : b) podemos referirnos a un ideal, a un fin inalcanzable pero que nos atrae como un imán: una sociedad armónica en cuyo seno cada cual pueda desplegar libremente todas sus potencialidades.

En este sentido, la fraternidad es bifronte como Jano: con una de sus caras mira esperanzado hacia el futuro que deberíamos construir y con la otra mira alerta el pasado desde el que hemos ido construyendo este presente. Una cara dicta un mandato; la otra describe un dato. De manera paradójica, la cara realista nos da el dato (lo dado) de que nada está dado de antemano y que, por lo tanto, todo es cuestión de construcciones, que nunca son definitivas, sino que son el dinámico resultado de luchas y consensos, de diálogos e imposiciones. Esta concepción a la vez armónica y conflictiva es propia de las ideologías políticas de más arraigo popular en la Argentina, como el peronismo y el radicalismo, tan difíciles de entender en otros países.

Toda extrapolación de lo privado a lo público tiene sus riesgos e inconvenientes, lo que ha llevado a muchos a desechar este concepto como categoría política útil. Por eso no debe perderse de vista que la fraternidad es una catacresis: no hace referencia a la familia. La tentación de pensarla como metáfora es muy fuerte, por eso es tan común encontrar su sentido banalizado. Sin embargo, la riqueza que podemos extraer de este concepto para comprender las ideologías políticas y las prácticas de nuestros movimientos sociales, sindicales, etc. es tan grande que bien vale la pena correr ese riesgo, aunque, claro está, con las debidas prevenciones. La primera de ellas es que, en la familia, los padres establecen la verticalidad que tiende a disolver el conflicto. En cambio, en el ámbito público no hay ni hubo nunca padre ni madre: no hay persona ni grupo que pueda detentar «naturalmente» la función paterna de establecer la ley, ni hay una sociedad-útero en cuyo seno maternal todo antagonismo se disuelve. La fraternidad universal nos advierte que la vida en común es una construcción que depende de nosotros, realidad originaria y a la vez ideal a alcanzar: en la tensión entre estos dos extremos se juega la existencia colectiva, existencia que no deja lugar a ingenuidades o banalizaciones. Nos señala que somos pueblo en el doble sentido del término: como populus o totalidad armónica de los de «arriba» y los de «abajo», de patricios y plebeyos, y como plebs, la parte de abajo, de los que pretenden erigirse en la representación del todo enfrentando al patriciado ${ }^{10}$.

${ }^{10}$ Digamos al pasar que plebs se refiere a la parte de la sociedad integrada por los más pobres, pero curiosamente tiene la misma etimología que pleno, plenitud. ¿Nos estará diciendo algo esta etimología acerca de pensar la plenitud si no es a partir de la falta, o de pensar la armonía si no es a partir del conflicto? 
No hay un padre que imponga su ley, sino que la vida en común es una construcción colectiva. Tampoco hay una madre-útero que nos contenga armónicamente a todos en su seno. No somos almas bellas capaces de vivir en un mundo sin conflictos una vez que hayamos acabado con «aquellos», los hijos de mala madre, que nos lo impiden. No tenemos más remedio que hacernos cargo de nuestra situación. Esto es lo que suele molestar de la fraternidad, y por eso se tiende a relegarla frente a principios fuertes como la libertad, la igualdad o la justicia. El problema es que esos principios nos hablan de un deber ser, mientras que la fraternidad nos obliga a confrontarnos con lo que es, con lo que somos, o, mejor dicho, con lo que estamos siendo. La libertad y la igualdad dejan de ser atributos debidos a la sustancia «hombre» para ser bienes que se pueden obtener, conservar o perder. Esto, por derecha molesta a quienes pretenden que las sociedades se encuentran naturalmente estratificadas, y por izquierda a las vanguardias iluminadas que tratan a los subalternados como a criaturas a las que hay que explicarles que están sometidos — pues si no, no lo sabrían - y cómo tienen que hacer para emanciparse. También molesta a quienes prefieren ignorar su responsabilidad esperando «que alguien haga algo». La fraternidad nos pone de cara ante el hecho de que siempre y necesariamente somos responsables, esto es: debemos dar respuesta. Si hubiese un padre, cuando llaman a nuestra puerta él se encargaría de responder. Pero no hay padre, por lo que aún nuestro silencio, nuestro quedarnos callados, es también una respuesta, aunque poco eficaz pues no se puede vivir siempre callado en casa por miedo al que llama. Los excluidos del festín llaman a la puerta de los satisfechos. Estos podrán encerrarse en sus barrios privados y elevar muros en torno a las autopistas que los lleven al centro. Pero los pobres, los indígenas, los afrodescendientes, los marginados de toda laya vuelven a llamar a la puerta cada vez que se los deja afuera.

Desde esta perspectiva, la fraternidad nos lleva a repensar la sociedad y, por ende, a resignificar la libertad, la igualdad y la justicia.

\section{LA LIBERTAD DEVIENE LIBERACIÓN}

Conforme esta concepción relacional, no se puede pensar en la libertad como una situación fija, sino como un proceso. No se es libre como si eso fuera parte de una supuesta naturaleza o esencia humana, sino que estamos siendo más o menos libres como resultado de luchas, acuerdos y consensos siempre inestables. La historia del pensamiento occidental muestra una clara preocupación por defender las libertades individuales ante los poderes, en especial religiosos y políticos (no tanto frente a los económicos) llegando a concebir implícitamente el poder como lo opuesto a la libertad. En cambio, 
desde la perspectiva que enunciamos acá, el poder es lo contrario a la impotencia, y la libertad es fruto de un proceso de construcción de poder (en especial frente a los poderes económicos) y no un estado o situación fija: por lo tanto, vista desde el prisma de la fraternidad, la libertad deviene liberación.

En otros términos, si olvidamos nuestra condición ineludiblemente fraternal podemos pensar que nuestra libertad es algo dado (sin que se sepa por quién y desde cuándo) cuyo límite está fijado por el inicio de la libertad de los demás. En ese caso, para ser libre por completo uno debería ser el único habitante del planeta siendo los demás el límite, el estorbo al pleno y absoluto ejercicio de nuestra libertad. Pero con la fraternidad advertimos que eso no es así, sino que la historia muestra que la libertad y las libertades se conquistan y se mantienen luchando junto a otros. No se trata de un atributo sustancial, sino de un proceso colectivo. Siempre se hace referencia a la vida y a lo común. No al ser, sino al estar siendo. Vale aclarar que no se trata de buscar una supuesta esencia de la libertad, sino que interesa señalar - por el contrario - que no existe dicha esencia, sino que la definición de la libertad, como ocurre con todo concepto político, es una construcción, un resultado de un juego de poder, y que, si ese juego lo jugamos asumiendo nuestra condición fraterna, vamos a dejar que salgan a la superficie elementos con una gran fuerza tanto heurística como performativa.

\section{LA IGUALDAD ENTENDIDA COMO JUSTICIA SOCIAL}

La permanencia y ubicuidad del conflicto y la primacía de la relación muestran que no es posible pensar en conseguir un estado de igualdad, una sociedad esencialmente igualitaria, sino que, desde esta perspectiva, parece más adecuado entender esas aspiraciones o anhelos igualitarios en términos de luchas por la justicia social. No vamos a definir qué es la justicia social. Como todo lo que de verdad importa —el amor, la libertad, el tiempo, la vida o el espacio-, la justicia social no es susceptible de ser aprehendida o aprisionada en los límites de una definición conceptual. Pero sí intentaremos describir las dimensiones que más se destacan en función de la fraternidad y su diferencia con las concepciones neoliberales ${ }^{11}$.

a) Justicia distributiva: La equidad en la distribución de la riqueza o de los ingresos es un componente necesario e indispensable en cualquier definición de justicia social, más aún: a la vista de las abismales desigualdades de riqueza e ingresos, hoy es el com-

\footnotetext{
${ }^{11}$ Como referencias para este apartado, tomo a Fraser (2012) y Mate (2011).
} 
ponente más importante, cuya no vigencia pone en riesgo la democracia y la misma vida en común en nuestro planeta. Pero no es suficiente. Es menester incluir otras dos dimensiones de la justicia social.

b) El reconocimiento: el homosexual, el indígena, el negro, la lesbiana y el judío pueden llegar a tener tanto dinero como el varón blanco heterosexual, pero si por su condición étnica, religiosa o preferencia sexual no son reconocidos sus derechos, ya sea por la ley o por las prácticas sociales, son víctimas de una injusticia. Esto ha sido suficientemente tratado por la teoría y la filosofía política, en especial gracias a los aportes de los estudios de género y culturales, por lo que no lo vamos a desarrollar acá ${ }^{12}$.

c) Justicia contributiva: El profesor universitario, el ejecutivo y el funcionario público retirado que recibe una buena jubilación y a quien todos los años se le hace un homenaje no padecen injusticias de las dos dimensiones anteriores. Tampoco las padece el trabajador desempleado que percibe un buen subsidio o la mujer del empresario que «vive para su familia». Pero ellos saben que pueden aportar mucho más a una sociedad que no les da la oportunidad de hacerlo. Esta es la dimensión que los medievales llamaban la «justicia general» y que la modernidad olvidó, por considerar al individuo como una sustancia en lugar de asumir que la persona se hace en su relación consigo misma, con los demás y con el resto de la naturaleza. Nos referimos acá a la dimensión de la justicia social que consiste en garantizar a cada uno el derecho a realizarse plenamente a través de su aporte a la realización de los demás. La ciencia y la filosofía modernas tienen una notoria incapacidad para advertir esta dimensión constitutiva del ser humano, por eso tienden a reducir la necesidad de hacer algo por los demás a la dimensión anterior de búsqueda de reconocimiento.

Un factor a tener en cuenta al hablar de justicia social en Argentina consiste en el conflicto que se deriva de la democratización del acceso a los bienes deseados, es decir, en general, el goce de las elites se vincula al no goce de la mayoría. Para que goce uno, el otro tiene que quedar al margen del goce. Por eso, lo primero que señalan los gobernantes neoliberales es que «la fiesta terminó»: «Les hicieron creer que podían vivir así eternamente» (diario Ámbito Financiero, 30/05/16), según Michetti, la vicepresidenta del gobierno encabezado por Macri, en sintonía con el presidente del Banco Central, González Fraga, para quien «Le hicieron creer al empleado medio que podía comprarse televisores de plasma y viajar al exterior» (idem), dejando en claro que esos son lujos solo reservados a las clases privilegiadas. Ahora bien, lo insoportable no es que «ahora

${ }^{12}$ Una excelente crítica de las políticas de reconocimiento del indígena y del afroamericano alentada por los organismos internacionales en América Latina puede verse en Gómez Michel, G. (2014). 
los de abajo coman y los ricos se queden con hambre», eso es jugar el mismo juego; lo insoportable es cambiar el juego: que los pobres tengan derecho a sentarse en la misma mesa que los ricos, a comer el mismo pan y a beber el mismo vino. Eso cambia las reglas: la democratización del goce es imperdonable.

En síntesis: para el pensamiento político popular en Argentina, la clásica tensión entre libertad e igualdad se diluye, pues se asume conceptualmente la liberación/proceso (no la libertad/estado) como el camino hacia la consecución de la justicia social.

\section{CONFLICTO Y ESTADO EN PERSPECTIVA LATINOAMERICANA}

La fraternidad universal nos dice que no hay un padre dador de sentido, sino que el sentido es el resultado de los conflictos ${ }^{13}$, las luchas y los acuerdos entre hermanos. El fundamento de la sociedad como tal no radica en nada estable; no es una sustancia, sino que está siendo constituido de manera constante por ese entramado relacional que es, obviamente, dinámico y contingente. En esa dinámica algunos sectores imponen su concepción de la realidad como la realidad o, al menos, como la concepción correcta y verdadera. No obstante, ni la política, ni la economía, ni la sexualidad, ni las igualdades o desigualdades de ninguna índole son dadas por la naturaleza. Nada está establecido de una vez y para siempre. Y se trata también de aceptar que el terreno de lo político no siempre se puede cimentar sobre el diálogo — diálogo que, en cambio, es siempre recomendable en el ámbito de la política y las políticas - , sino que se funda sin fundamento ${ }^{14}$ (Poratti, 1993).

En los países centrales no faltan quienes creen que se puede resolver el problema de la ausencia del fundamento apelando al diálogo y al consenso en torno a los procedimientos para tomar las decisiones políticas. Por cierto, si olvidamos la dimensión conflictiva de la fraternidad, podemos caer sin esfuerzo en esas posturas ingenuamente dialogadoras o deliberativas que creen que «todo conflicto puede canalizarse si las partes defienden con inteligencia su propio interés». Ello sería posible si las partes fuesen capaces de defender sus intereses con inteligencia, pero - como muestra tanto la historia como la experiencia cotidiana - el conflicto tiende a nublar la inteligencia, que no pocas veces cede su lugar a las pasiones más destructivas.

13 Sobre el conflicto como instituidor de la sociedad, ver Marchant (2009: 126).

${ }_{14}$ Para una introducción a la constelación de pensadores postfundacionales, en especial los llamados postestructuralistas, ver Stavrakakis (2010) y Marchart (2009). Para el problema del fundamento en la Grecia clásica desde la perspectiva de la filosofía popular argentina, ver Poratti (1993). 
No obstante, no es este el principal obstáculo a la canalización del conflicto. En efecto, podría existir un tercero imparcial que conserve la razón y de algún modo imponga a las partes una solución beneficiosa para todos. El problema mayor radica en que nadie conoce en realidad su propio interés. Abundan los cuentos y mitos que relatan la desgracia que acontece a quienes ven su deseo cumplido. Ocurre que aquello que nosotros creemos que es «nuestro propio interés» difícilmente sea tal. Por lo general, es el interés de los sectores hegemónicos de la sociedad.

Por desgracia, no es verdad que «dialogando la gente se entiende y puede llegar a acuerdos satisfactorios para todas las partes», pues para que ello fuera posible se requeriría que todos supieran de verdad qué quieren; que supieran expresar efectivamente eso que quieren y que los otros pudieran entender esa demanda con exactitud (Zizek, 2013: 25). Este problema se agudiza cuando nos referimos no ya a los deseos individuales sino a las demandas colectivas: allí interviene el tercero indeterminado, por lo que aun suponiendo que a través de un profundo conocimiento de sí algunos supiesen qué es lo que desean de verdad, y a través de un diálogo claro y sincero el otro pudiese entender y satisfacer esa demanda, siempre aparecerían otros afectados directa o indirectamente por esa decisión.

El olvido de estos factores lleva a reducir el problema del conflicto político, social y económico contemporáneo a una mera cuestión de debate público, donde se trataría de acordar sobre proposiciones y definiciones para llegar a acuerdos y consensos. Hay una mala noticia: las cosas son bastante más complejas. La gran trampa del neoliberalismo como ideología hegemónica del capitalismo de consumo - a diferencia del liberalismo tradicional propio del capitalismo de acumulación - consiste en hacernos creer que siempre tenemos claro lo que queremos y que ese deseo brota espontáneamente de cada uno. Pero hay también una buena noticia: el conflicto no es sinónimo de lucha a muerte, sino que es precisamente lo que hace que vivamos en sociedad. Un ejemplo que es susceptible de varias objeciones, pero que funciona para explicar lo central de esta tesis, es que sin la rivalidad entre equipos de fútbol no existiría el fútbol. La dificultad para aplicar de un modo directo el ejemplo es que en una sociedad no hay un minuto cero, un momento anterior al campeonato donde puedan fijarse las reglas, sino que estamos todo el tiempo jugando el campeonato con las reglas que a cada instante consiguen imponer los que tienen el poder de hacerlo; de esto se trata la hegemonía. Claro que sin reglas todo es peor: la ley es siempre una imposición de los más fuertes, pero de un modo $\mathrm{u}$ otro aun los más fuertes deben al menos fingir que se atienen a esa ley. La inexistencia de una ley equivaldría a la constante y explícita realización de la mera voluntad de los más fuertes. 
Esto nos lleva a plantear la problemática del Estado. Desde Hobbes en adelante, pasando en modo eminente por Hegel, a medida que las sociedades se secularizan el Estado va ocupando el lugar de Dios. De un Dios concebido a imagen y semejanza del sujeto moderno: varón, uno, soberano, omnipotente. En consecuencia, si Dios es uno y solo secundariamente trino, el Estado también es en primer término uno y secundariamente trino (poderes ejecutivo, legislativo y judicial). Dios es soberano, está super omnes, está sobre todo, ergo el Estado es soberano. Dios es omnipotente, el Estado es omnipotente. En este contexto hablar de soberanía popular no es más que mera demagogia sin fundamento alguno. Pero si en vez de entender al Dios uno, único, exclusivo, excluyente, super omnes; un Dios, en fin, de una totalidad totalizante; si en vez de pensar en ese Dios pensamos en el Dios trino (o sea, en un Dios que es relación antes que sustancia, que es como lo concibe la religiosidad popular latinoamericana) y por lo tanto pensamos en el Estado como relación, ya la reflexión se abre hacia otros horizontes. Hasta ahora se tiende a pensar en la soberanía como una cualidad del poder del Estado, pero si pensamos en el Estado como relación, la soberanía también es constitutiva de esa relación y no cualidad de una sustancia. Esta noción de soberanía como relación nos permite entender la soberanía estatal «hacia adentro» (ad intra), como la relación entre los tres elementos que componen el Estado: territorio, población y gobierno. Así, cuando el gobierno se relaciona con el pueblo, lo podemos analizar en términos de soberanía popular, y, cuando el gobierno y el pueblo se relacionan con el territorio, lo podemos estudiar en términos de soberanía ecológica. Desde esta perspectiva podemos afirmar que «hacia fuera» (ad extra) un Estado es más soberano cuanto más y mejor se vincule con otros Estados (Del Percio, 2014: 196). Una concepción fraterna de la soberanía no propone que los Estados se han de comportar como buenos hermanos que solo anhelan el bien de los demás. Lo que quiere significar es que ningún Estado puede ocupar el lugar del padre, sino que las relaciones son horizontales. Asimétricas, pero horizontales, como ocurre entre los hermanos.

El ideal fundacional de los líderes del proceso emancipador americano, como San Martín, Artigas o Bolívar, era construir una América unida. No era un capricho, ni una idea abstracta elaborada por académicos, ni resultado de una ideología: era un ideal concordante con la comprensión y el sentir más profundo de nuestros pueblos. No había entonces ni hay ahora otro modo más eficaz de enfrentar la conjunción de intereses contrarios a la plena realización de cada persona y de cada pueblo. La filosofía de la liberación, el pensamiento decolonial y otras constelaciones concomitantes constituyen claras formas contemporáneas de expresión intelectual de ese ideal emancipador. 


\section{BIBLIOGRAFÍA}

Alemán, Jorge (2016). Horizontes neoliberales en la subjetividad, Buenos Aires: Grama.

Buber, Martin (1993). Yo y Tú, Madrid: Caparrós Editores.

Casalla, Mario (1998). El Sujeto Cartesiano, Buenos Aires: Edición de la Facultad de Psicología - UBA.

Castro Gómez, Santiago y Grosfoguel, Ramón (2007). El giro decolonial. Reflexiones para una diversidad epistémica más allá del capitalismo global. Bogotá: Siglo del Hombre.

Contreras Nátera, Miguel A. (2014). Otro modo del ser o más allá del euroccidentalismo, Caracas: CELARG.

Cuda, Emilce (2016). Para leer a Francisco. Teología, ética y política. Buenos Aires: Manantial.

Cullen, Carlos (2017). Reflexiones desde nuestra América. Buenos Aires: Las cuarenta.

Del Percio, Enrique (2014). Ineludible fraternidad. Conflicto, poder y deseo, Buenos Aires: CICCUS.

Dussel, Enrique (2001). Ética de la liberación. Madrid: Trotta.

Esposito, Roberto (2006). Bíos. Biopolítica y filosofía, Buenos Aires: Amorrortu.

Estermann, Josef (1998). Filosofía Andina. Quito: Abya Yala.

Estermann, Josef (2008). Si el sur fuera el norte, La Paz: ISEAT.

Galli, Carlo (2013). El malestar de la democracia. Buenos Aires: FCE.

García Delgado, Daniel y Molina, D. «Ética y Desarrollo. El conflicto de las interpretaciones». En Scannone, J. y García Delgado, D. (Comps.). Ética, desarrollo y región. Buenos Aires: CICCUS.

Gómez Michel, Gerardo (2014). «La tercera raíz. La construcción del imaginario identitario afrolatinoamericano ante los retos de la interculturalidad» En Gómez Michel et al.; Neoliberalism and Post-neoliberalism. Challenge and Response from Latin America, Busan: Institute of Iberoamerican Studies, Busan University.

Foucault, Michel (2007). Nacimiento de la biopolítica, Buenos Aires: FCE.

Fraser, Nancy (2012). Escalas de justicia. Buenos Aires: Herder.

Grondona, Mariano (1999). Las condiciones culturales del desarrollo económico. Buenos Aires: Planeta.

Habermas, Jurgen (1999). Problemas de legitimación en el capitalismo tardío. Madrid: Cátedra.

Hayek, Friederich (2007). Camino de servidumbre, Madrid: Alianza Editorial. Houellebecq, Michel (1999). Las partículas elementales, Barcelona: Anagrama. 
Kusch, Rodolfo (2008). La negación en el pensamiento popular, Buenos Aires: Las cuarenta.

Kusch, Rodolfo (1976). Geocultura del hombre americano, Buenos Aires: García Cambeiro.

Marchart, Olivier (2009). El pensamiento político posfundacional, Buenos Aires: FCE.

Mate, Manuel R. (2011). Tratado de la injusticia, Barcelona: Anthropos. Barcelona.

Moreno, Alejandro (1995). El aro y la trama. Episteme, modernidad y pueblo, Miami: Rafael Luciani.

Mouffe, Chantall (1999). El retorno de lo político, Barcelona: Paidós.

Poratti, A. (2009). «El antiproyecto de la sumisión al norte imperial» en Cirigliano, G. et al.; Proyecto Umbral. Resignificar el pasado para conquistar el futuro, Buenos Aires. CICCUS.

Poratti, Armando (1993). Diálogo, Comunidad y Fundamento. Política y metafísica en el Platón inicial, Buenos Aires: Biblos.

Sabrovsky, Eduardo (2013). Chile, tiempos interesantes. A 40 años del golpe militar. Santiago de Chile: Universidad Diego Portales.

Scannone, Juan Carlos (2005) Religión y nuevo pensamiento. Hacia una filosofía de la religión para nuestro tiempo desde América Latina. Barcelona: Anthropos.

Sloterdijk, Peter (2002). El desprecio de las masas. Ensayo sobre las luchas culturales de la sociedad moderna, Valencia: Pretextos.

Stavrakakis, Yannis (2010). La izquierda lacaniana, Buenos Aires: FCE.

Tristán, Flora. Peregrinaciones de una paria, accesible en: http://sisbib.unmsm.edu.pe/ bibvirtual/libros/literatura/pereg_paria/contenido.htm

Žižek, Slavoj (2013) El más sublime de los histéricos, Buenos Aires: Siglo XXI. 